\title{
EOLÉTIOA Volume 33,2013 químico \\ DIAGNÓSTICO AMBIENTAL DE METAIS NO SEDIMENTO DE CÓRREGOS ADJACENTES A ÁREAS DE CULTIVO DE BANANA (MUSA SPP.) NO ESTADO DE SÃO PAULO, BRASIL
}

\author{
Juliano José Corbi ${ }^{1}$, Priscila Kleine ${ }^{2}$, Susana Trivinho Strixino ${ }^{2}$ e Ademir dos Santos ${ }^{3}$.
}

\begin{abstract}
${ }^{1}$ Departamento de Hidráulica e Saneamento - SHS, Universidade de São Paulo - USP, C.P. 359 CEP 13566-590, São Carlos - SP, Brasil. Email: julianocorbi@usp.br. ${ }^{2}$ Departamento de Hidrobiologia, Universidade Federal de São Carlos - UFSCar, C.P. 676, 13560-970, São Carlos-SP. ${ }^{3}$ Departamento de Química Analítica, Instituto de Química de Araraquara, Universidade Estadual Paulista - UNESP, C.P 355, 14800-970, Araraquara-SP. Endereço eletrônico: julianocorbi@usp.br
\end{abstract}

O Brasil é o segundo maior produtor de bananas do mundo. O Estado de São Paulo é o maior produtor nacional, produzindo e colhendo 1,17 milhões de toneladas por ano, principalmente na região do Vale do Ribeira, onde se concentra 64,60\% da área de produção da fruta do estado. Nesta área, 33.113 ha são destinados à produção de 810.000 mil toneladas de banana por ano. A utilização de fertilizantes durante o cultivo da banana, aliado ao desmatamento das matas ciliares, pode ser responsável por impactos nos recursos hídricos das áreas adjacentes. Este estudo apresentou como objetivo, avaliar o possível impacto do cultivo de banana no sedimento de 10 córregos analisando os metais $\mathrm{Cd}, \mathrm{Cu}, \mathrm{Zn}, \mathrm{Fe}, \mathrm{Mn}, \mathrm{Cr}$ e $\mathrm{Ni}$ comumente utilizados em fertilizantes. Os resultados desse estudo apontam para maiores concentrações de metais em córregos com cultivo de banana quando comparado aos córregos florestados. No entanto, com exceção do $\mathrm{Ni}$, as concentrações dos metais detectados estão abaixo dos valores-guia de qualidade de sedimentos aquáticos (VGQSs), TEL (valores limiares de efeito) e PEL (valores prováveis de efeito).

Palavras-chave: cultivo de banana; metais; córregos; sedimentos

\begin{abstract}
:
The State of São Paulo is the great banana producer with 1.17 million tons per year. In this area, 33.113 ha are destined to the production of 810.000 tons of banana. The use fertilizers in the banana plant cultivation, in addition with deforestation of riparian vegetation are responsible for impacts on the hydric resources. This work deals with the possible impact of banana activity in the sediments of 10 streams by the study of 7 metals $(\mathrm{Cd}, \mathrm{Cu}, \mathrm{Zn}, \mathrm{Fe}, \mathrm{Mn}, \mathrm{Cr}$ and $\mathrm{Ni})$. The results show that there is a higher concentration of metals in streams with banana cultivation than forested streams. Although, with exception of $\mathrm{Ni}$, the values of metals detected are above to the Threshold Effect Level (TEL) and the Probable Effect Level (PEL) for sediments.
\end{abstract}

Keywords: banana; sediment; metals; streams. 
Introdução

Os recursos hídricos caracterizam-se como os mais facilmente afetados pelas atividades antrópicas, seja pelo comprometimento de sua qualidade e/ou quantidade, ou pelo comprometimento de suas características, como alteração de cursos de drenagem [1] e na modificação no aporte de nutrientes [2]. Estes sistemas aquáticos funcionam como reservatórios temporários ou finais de uma grande variedade e quantidade de poluentes lançados no solo das áreas adjacentes ou diretamente nos corpos d'água, especialmente por atividades agrícolas [3-6].

O Brasil é o segundo maior produtor de banana do mundo, perdendo apenas para Índia, sendo que a maior parte da produção destina-se ao mercado interno [7]. Atualmente, no Brasil, o cultivo da banana é realizado em muitos estados, destacando-se os das regiões Sudeste (São Paulo e Minas Gerais) e Nordeste (Bahia, Ceará e Rio Grande do Norte) [7]. O Estado de São Paulo é o maior produtor de banana do país, produzindo e colhendo 1,17 milhões de toneladas por ano, principalmente na região do Vale do Ribeira, onde se concentra $64,6 \%$ da área de produção da fruta no Estado. Nesta área, 33.113 ha são destinados à produção de 810 mil toneladas de banana por ano [8]. A banana (Musa spp.) é uma das frutas mais consumidas no mundo, sendo o quarto alimento mais utilizado, ficando atrás apenas do arroz, trigo e milho. Este sucesso é devido a muitas vantagens, como por exemplo, pelo fato de amadurecer aos poucos, facilitando a colheita, o transporte e o aproveitamento [7]. A banana é oriunda do sudeste asiático, de onde se disseminou posteriormente para outras regiões da Ásia, para a Índia e África, há milhares de anos. No início do século XVI, os europeus a introduziram na América e Antilhas, mas foi apenas na $2^{\mathrm{a}}$ metade do século XIX que a fruta ganhou expressão no comércio mundial, com o estabelecimento de grandes produções no Caribe e na América Central. Na atualidade, devido à sua grande adaptação, seu cultivo é amplamente distribuído tanto nos trópicos como nos subtrópicos, sendo que as maiores áreas de cultivo comerciais são encontradas nos trópicos úmidos [9].

A bananicultura é uma cultura perene, não havendo o corte total da vegetação (Embrapa Mandioca e Fruticultura Tropical, 2007), o que proporciona a manutenção de parte da cobertura vegetal e conseqüentemente o sombreamento aos corpos d'água adjacentes. Esta atividade agrícola é pouco mecanizada, que utiliza intensivamente mão de obra tanto na colheita como na póscolheita do produto [10]. No entanto, a cultura de banana necessita de adubação através da aplicação de fertilizantes contendo nitrogênio, fósforo e potássio $(\mathrm{N}, \mathrm{P}, \mathrm{K})$, mas também ricos em diferentes tipos de metais tais como, $\mathrm{Pb}, \mathrm{Ni}, \mathrm{Cr}$ e Cd [11]. Estes compostos são essenciais para uma boa produção. Entretanto, a aplicação excessiva pode contaminar o sedimento aquático e ser tóxica tanto para a cultura de banana como para a biota aquática e terrestre $[4,5,12,13]$. Outro problema decorrente desta atividade agrícola, é que embora seu cultivo comercial seja recomendado preferencialmente para terrenos planos, a maioria dos plantios de banana do Brasil localiza-se em áreas de declividade acentuada, o que exige a adoção de práticas de conservação do solo, geralmente não implantadas [14]. Na região do Vale do Ribeira este problema é agravado, pois nesta área o índice pluviométrico é alto, com precipitação anual de 1.200 a 2.000 mm/ano, e há uma grande concentração de corpos d'água, nascentes ou afluentes de rios de grande importância estadual como o rio ibeira do Iguape, Ribeirão do Cunha, Guaraú, Itapiraguí, Jacupiranga, entre outros.

Pouco se conhece a respeito das conseqüências do manejo e dos possíveis impactos dessa cultura, embora ela seja encontrada em grandes áreas do Estado de São Paulo, principalmente na Mata Atlântica (litoral brasileiro), bioma que é considerado um dos mais fragmentados e ameaçados do mundo e considerado como um hotspot mundial [15]. Tendo em vista a falta de estudos sobre os possíveis impactos desta atividade agrícola e no intuito de reunir informações a respeito das 
conseqüências ambientais do cultivo de banana, no presente estudo foi analisada a presença dos metais $\mathrm{Cu}, \mathrm{Fe}, \mathrm{Cd}, \mathrm{Zn}, \mathrm{Mn}, \mathrm{Cr}$ e $\mathrm{Ni}$ no sedimento de 10 córregos da região do Vale do Ribeira e litoral sul de São Paulo (Brasil), englobados em duas situações distintas: cinco córregos localizados em áreas florestadas e preservadas (Reserva Municipal do Mandira, no município de Cananéia) e cinco em áreas de cultivo de banana, sem mata ciliar (dois no município de Cajati e três no município de Jacupiranga). A escolha do sedimento como meio de investigação deve-se ao fato deste desempenhar um papel importante na determinação da poluição por metais de ambientes lóticos [16]. Os sedimentos têm sido considerados como um compartimento importante como fonte ou sumidouro de nutrientes e contaminantes no ambiente aquático, de acordo com a sua composição química e propriedades biogeoquímicas [16]. Dessa forma, o sedimento reflete a qualidade corrente do sistema aquático e pode ser usado para detectar a presença de contaminantes que não permanecem solúveis após seu lançamento em águas superficiais [12-16].

Em virtude da importância de uma avaliação integrada e hierárquica, que combinam dados com base em várias linhas de evidência, para a avaliação da qualidade de sedimentos aquáticos [17], os resultados obtidos das concentrações de metais do sedimento dos 10 córregos foram comparados com os níveis limiares de efeito "TEL" (do inglês "Thereshold Effect Level") e com os níveis prováveis de efeito "PEL" (do inglês "Probable Effect level").

\section{Procedimentos experimentais}

\section{Local de estudo}

O estudo foi desenvolvido em 10 córregos localizados nos Municípios de Cananéia, Jacupiranga e Cajati (Estado de São Paulo), onde a atividade de cultivo de banana é intensa (Figura 1). O clima da região, segundo a classificação de Köppen, é o clima tipo Cfa, isto é, tropical úmido, sem estação seca, sendo a temperatura do mês mais quente superior a $22^{\circ} \mathrm{C}$, podendo chegar a $35^{\circ} \mathrm{C}$. A pluviosidade varia de 1.200 a $2.000 \mathrm{~mm}$ anuais, sendo fevereiro o mês mais chuvoso e julho o mais seco [18]. O Vale do Ribeira possui em grande parte do seu território, um relevo ondulado e montanhoso com grandes desníveis altimétricos, assentados predominantemente sobre rochas calcárias [19-20].

Neste estudo foram selecionados 10 córregos, todos de baixa ordem $\left(1^{\mathrm{a}}\right.$ a $3^{\mathrm{a}}$ ordem), que nascem em uma mesma região e correm para o litoral e apresentam pequena profundidade $(<1,5$ $\mathrm{m})$, pequena largura $(<2 \mathrm{~m})$ e baixa velocidade da água $(<2 \mathrm{~m} / \mathrm{s})$. Estes córregos estão situados entre as coordenadas S $24^{\circ} 50^{\prime} 6^{\prime \prime}$ a S $24^{\circ} 59^{\prime} 48^{\prime \prime}$ e W $48^{\circ} 00^{\prime} 13^{\prime \prime}$ a W 4859'53" (Tabela I). Os córregos situados nas áreas adjacentes ao cultivo de banana (córregos B1 a B5) apresentam substrato arenoso (em torno de $15 \%$ ), com a presença de cascalhos (pedras com 2 a $256 \mathrm{~mm}$ de diâmetro) e um número pequeno de matacões (pedras com diâmetro acima de $256 \mathrm{~mm}$ ). Apresentam também pequenas quantidades de restos de folhas e pseudotroncos da plantação. Os corpos d'água das áreas florestadas (córregos M1 a M5) possuem substrato pedregoso, com grande quantidade de cascalhos e matacões. Restos vegetais em pequenas quantidades (folhas e galhos) da mata ripícola compõem o substrato orgânico. Todos os córregos estudados apresentam águas límpidas e estão livres de outros impactos antrópicos como atividades industriais e domésticas. 


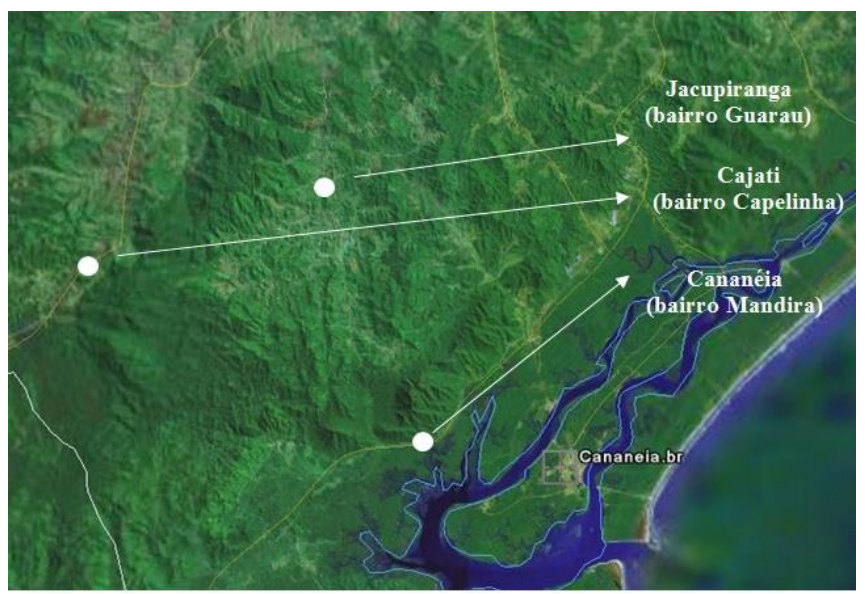

Figura 1. Imagem de Satélite, com indicação das cidades de Jacupiranga, Cajati e Cananéia - Região do Vale do Ribeira e Litoral Sul do Estado de São Paulo, Brasil (Fonte: Google Earth).

\section{Caracterização ambiental}

Primeiramente, em cada córrego, foi feita uma caracterização ambiental dos córregos através do preenchimento do protocolo do grupo de pesquisa do projeto Biota-FAPESP, no qual foram anotadas as informações sobre características do córrego como localização, bacia hidrográfica, ordem do córrego, largura (em metros), profundidade (em centímetros), substrato predominante e as características do entorno como o tipo de vegetação ripária, cobertura do dossel e alterações da paisagem. Adicionalmente, foram medidas as principais variáveis físicas e químicas da água como oxigênio dissolvido (mg.L-1), temperatura (oC), condutividade elétrica, $\mathrm{pH}$ e turbidez, com auxílio do multisensor da marca Yellow Springs, modelo 556. Também foi realizada uma caracterização geral do sedimento dos córregos especialmente sobre a composição granulométrica e matéria orgânica.

\section{Procedimentos analíticos}

As amostras de sedimento superficial foram coletadas nos 10 córregos no período de estiagem, entre outubro e novembro de 2005. As amostras foram coletadas com auxílio de uma draga do tipo Ekman-Birge $(225 \mathrm{~cm} 2)$ em três diferentes pontos de cada córrego, a uma profundidade variando de 0,2 a 0,4 m. Para a preparação das amostras para análise, foi utilizada água deionizada, duplamente destilada (DDDW). Todos os ácidos adquiridos da Merck® e toda a vidraria utilizada foi previamente lavada com jato de ácido nítrico concentrado [21].

Neste estudo foram analisados os metais que geralmente estão associados a diferentes fertilizantes, como chumbo, cobre, zinco, cromo, manganês, magnésio, níquel e ferro como apontado anteriormente em diferentes estudos $[5,11,19,22]$. Optou-se pela análise dos metais potencialmente biodisponíveis por ser a parcela de metais que podem ser potencialmente utilizados pela biota ou se acumularem em seu organismo.

A extração de metais potencialmente biodisponíveis $(\mathrm{Cd}, \mathrm{Cu}, \mathrm{Zn}, \mathrm{Fe}, \mathrm{Mn}, \mathrm{Cr}$ e $\mathrm{Ni}$ ) seguiu a metodologia descrita [12,16,23]. Dessa forma, aproximadamente $2,5 \mathrm{~g}$ de sedimento seco $\left(a 0^{\circ} \mathrm{C}\right.$ ) foram colocados em um frasco de 100 $\mathrm{mL}$ com tampa rosqueável e adicionaram-se 50,0 $\mathrm{mL}$ de solução de ácido clorídrico $0,10 \mathrm{~mol} \mathrm{L-1}$. A mistura foi mantida por duas horas em mesa agitadora de movimento circular horizontal com rotação de 200 RPM. Após o repouso para decantação do material sólido, filtrou-se a solução em papel Whatman e armazenou-se em Becker de $100 \mathrm{~mL}$. A solução resultante das extrações foi analisada por espectrofotometria de absorção atômica convencional (modelo Perkin Elmer AAnalyst 300). As digestões e as detecções foram feitas em triplicatas.

\section{Análise Estatística}

Para se verificar a significância dos dados obtidos nesse estudo, foi aplicado um teste estatístico não paramétrico de Kruskal-Wallis (ANOVA), complementado pelo teste de Dunn, sobre as concentrações de metais obtidas no sedimento. O teste foi aplicado para os valores obtidos de metais potencialmente biodisponíveis no sedimento aquático dos 10 córregos.

\section{Resultados}




\section{Caracterização ambiental}

$\mathrm{O}$ oxigênio dissolvido (O2) apresentou concentrações elevadas em todos os córregos analisados, mas com valores um pouco mais baixos nos córregos localizados em áreas com atividade de banana, sem mata ciliar. Os valores variaram de 7.87 mg.L-1 no córrego B3 para 10.3 mg.L-1 no córrego B2, ambos situados nas áreas com cultivo da banana. Os valores da condutividade elétrica foram mais elevados nas áreas com cultivo da banana se comparado com as áreas preservadas. Os valores mais elevados foram detectados para o córrego B1 e o córrego B4, em contrapartida os menores valores foram detectados para córregos de M1 e de M2. Os valores da condutividade elétrica variaram de 0.03 ( $\mu \mathrm{S} . \mathrm{cm}-1)$ a $1.50(\mu \mathrm{S} . \mathrm{cm}-1)$. Da mesma forma, a temperatura foi mais elevada nas áreas com cultivo da banana se comparado com as áreas preservadas.

As concentrações das variáveis físicas e químicas da água além de outras características dos 10 córregos são apresentadas na Tabela I.

\section{Metais potencialmente biodisponíveis}

Os córregos localizados nas áreas adjacentes aos cultivos de banana sem mata ciliar apresentaram concentração mais elevadas dos metais analisados. Os metais potencialmente biodisponíveis foram detectados na maioria dos córregos analisados. As concentrações destes metais apresentaram diferenças significativas de acordo com o tipo de vegetação do entorno ou do uso do solo ( $\mathrm{p}<0,05$ ), sendo que as maiores concentrações foram detectadas, em geral, nos córregos adjacentes aos córregos com cultivo de banana (Tabela II). Da mesma forma, no geral, as concentrações médias de zinco, crômio, manganês magnésio, chumbo e níquel observadas no sedimento dos córregos com cultivo de banana sem mata ciliar foram mais elevadas quando comparadas com córregos localizados em áreas de pastagem e com atividade canavieira no Estado de São Paulo (Tabela III). O crômio e o níquel apresentaram valores mais elevados nos córregos de bananicultura, sem mata ciliar. De forma semelhante, o zinco e o cobre também apresenataram concentrações mais elevadas nos córregos situados em áreas com cultivo de banana, sem mata ciliar, quando comparados com os córregos localizados em área com mata ciliar preservada (Tabela III).

O ferro, o magnésio e o manganês foram detectados em elevadas concentrações em todos os córregos, porém, também com valores mais elevados nos córregos impactados. Embora as concentrações de metais nos córregos de bananicultura tenham sido mais elevadas, estes valores estão abaixo dos valores de referência de qualidade para solos ou abaixo dos valores permitidos em áreas agrícolas, segundo o relatório divulgado pela Cetesb (2005). Para ferro, manganês e magnésio não existem valores de referência, pois estes são elementos típicos do solo e podem ser encontrados em diferentes concentrações de acordo com a região. No entanto, especialmente $\mathrm{Mn}$ e $\mathrm{Mg}$ foram detectados em concentrações médias mais elevadas nos córregos com bananicultura, com valores em torno de 350 mg.kg-1 e 396 mg.kg-1 respectivamente (Tabela III). Os valores das concentrações dos metais e seus respectivos desvio-padrão podem ser observados na figura 2.

O teste estatístico Kruskal-Wallis (ANOVA) aplicado sobre as concentrações de metais dos 10 córregos apontou para diferenças significativas entre os córregos situados em áreas preservadas e com atividade de banana, sem mata ciliar. As diferenças foram extremamente significativas para os córregos M3, M4 e M5 e os córregos com cultivo de banana. 


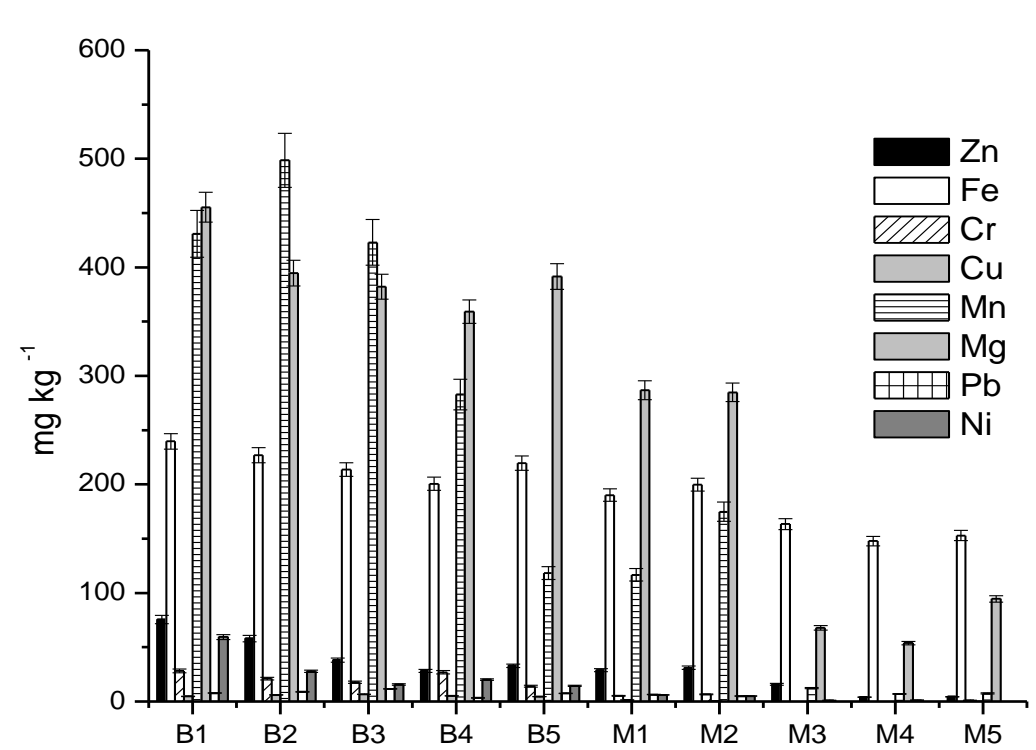

Figura 2. Concentrações médias e respectivos desviospadrão, dos metais potencialmente biodisponíveis (mg.kg-1) no sedimento dos 5 córregos em áreas de bananicultura (B1-B5) e 5 córregos em áreas florestadas (M1-M5).

$*_{\text {valores de } \mathrm{Fe}=10^{-1}}$

\section{Discussão}

As concentrações de metais nos sedimentos dos córregos analisados apresentaram diferenças de acordo com os usos da terra nas áreas adjacentes (banana com mata ciliar e banana sem mata ciliar). No geral, as concentrações de zinco, crômio, manganês magnésio, chumbo e níquel observadas no sedimento dos córregos com cultivo de banana sem mata ciliar foram mais elevadas quando comparadas com córregos localizados em áreas de cultivo com mata ciliar preservada e quando comparadas com áreas de pastagem e com atividade canavieira no Estado de São Paulo.

As concentrações dos metais foram especialmente mais elevadas para os elementos $\mathrm{Mn}, \mathrm{Mg}, \mathrm{Pb}$ e Ni. Sobretudo o níquel, apresentou concentração acima dos valores-guia para a qualidade de sedimentos (níveis limiares de efeito ou "TEL"), com concentrações, em geral, acima de 10,0 mg.kg-1. A presença de chumbo no sedimento dos córregos com cultivo de banana sem mata ciliar também é preocupante, uma vez que esse elemento potencialmente tóxico não é essencial aos seres vivos e, além disso, é um elemento mutagênico. A presença desse metal no sedimento e sua provável bioacumulação por toda a cadeia trófica especialmente em insetos $[4,5,6] \mathrm{e}$ peixes torna clara a necessidade de um manejo adequado dessas áreas, com o rápido reflorestamento das matas ciliares e modificações na forma de cultivo de banana. No entanto, a maioria das concentrações de metais detectadas no sedimento dos 10 córregos, estão abaixo dos valores-guia de qualidade para sedimentos (VGQSs) como apontado em outros estudos [17].

$\mathrm{O}$ crômio e o níquel apresentaram valores mais elevados nos córregos de bananicultura sem mata ciliar. As elevadas concentrações destes metais estão em concordância com observações de outros pesquisadores para córregos desmatados com atividades agrícolas [4,24,25]. O crômio raramente é encontrado nas águas naturais, contudo pode ocorrer como contaminante das águas sujeitas a poluição de despejos de curtumes, de indústrias e de circulação de águas de refrigeração onde é usado para o controle da corrosão [26,27]. O níquel é um elemento relativamente raro e corresponde a apenas $0,01 \%$ da massa da crosta terrestre. É utilizado principalmente na fabricação de aços especiais e é usado também como catalisador nas indústrias química, farmacêutica e alimentícia [27]. No entanto, observamos que as concentrações desse metal no sedimento foram mais elevadas nos córregos localizados em áreas com atividades de banana, sem mata ciliar se comparado com outras situações ambientais. Apesar desse elemento não ser considerado tóxico em baixas concentrações (valores menores que 13 mg.kg-1) a concentração obtida no presente estudo aponta novamente para a toxicidade dos seres vivos.

O cobre e o zinco também apresentaram concentrações mais elevadas em áreas com atividade de banana. A contaminação por cobre pode ter origem nos esgotos domésticos e industriais ou se originar por lixiviação de produtos agrícolas através das chuvas [24]. Por outro lado, os altos valores de zinco também foram observados por outros pesquisadores em áreas agrícolas desmatadas [4,5,28]. Como todos 
os córregos analisados estão localizados na mesma bacia hidrográfica e assentados em terrenos geologicamente similares, os valores mais elevados destes metais nos sedimentos dos córregos relacionados com o plantio de banana parecem confirmar a influência dessa atividade agrícola sobre o entorno, embora a retirada da mata ciliar e a conseqüente lixiviação do solo não devam ser ignoradas. Os valores menores de $\mathrm{Cu}$ e Zn nos sedimentos dos córregos protegidos por mata ciliar concordam com resultados obtidos [4,5,6,12] para os córregos situados em áreas preservadas com mata ciliar da região central do estado de São Paulo.

Como descrito por alguns pesquisadores [17], há valores de referência para a avaliação da qualidade dos sedimentos conhecidos como valores-guia de qualidade de sedimentos (VGQSs). Esses valores permitem, de certa forma, apontar a toxicidade potencial destes elementos às comunidades bentônicas. Para o cromio, os níveis limiares de efeito (TEL) e os níveis prováveis de efeito (PEL) são respectivamente $37.3 \mathrm{mg} . \mathrm{kg}-1 \mathrm{e}$ 90.0 mg.kg-1. No presente estudo, os valores obtidos de cromio para o sedimento dos córregos variaram entre 0,99 mg.kg-1 (córrego M5) a 28,99 mg.kg-1 (córrego B1), portanto, abaixo dos valores-guia (VGQSs). Para o zinco os níveis limiares de efeito (TEL) e os níveis prováveis de efeito (PEL) são respectivamente 123,10 mg.kg-1 e 315,00 mg.kg-1. No presente estudo, os valores detectados variaram entre 4,06 mg.kg-1 (M4) a 75,42 mg.kg-1 (B1), evidenciando valores abaixo dos valores-guia. O Cobre apresenta os níveis limiares de efeito (TEL) e os níveis prováveis de efeito (PEL) entre 35,70 mg.kg-1 e 197,00 mg.kg1 respectivamente. Os valores obtidos neste trabalho também estão abaixo dos valores-guia sendo que a maior concentração foi de 6,62 mg.kg-1 (córrego B3) e a menor concentração foi observada par o córrego M5 com concentração de 0,14 mg.kg-1. Dos metais analisados, apenas o níquel foi detectado em concentrações mais elevadas quando comparados aos valores-guia. Os valores detectados variaram de 4,97 mg.kg-1 (córrego M2) a 59,37 mg.kg-1 (córrego B1), sendo que os valores-guia variam de $18,00 \mathrm{mg} . \mathrm{kg}$ 1 para o TEL e 35,90 mg.kg-1 para o PEL. A toxicidade raramente ocorre abaixo dos valores do TEL, mas ocorrem frequentemente acima do PEL, e se os valores estiverem entre os dois níveis a toxicidade pode ocorrer [17]. Existem também valores-guia propostos pela Cetesb [29] que adotam uma escala de ótimo a péssima de acordo com determinadas concentrações observadas no sedimento aquático. Pelos dados obtidos no presente estudo, os córregos estão enquadrados entre ótima e boa qualidade do sedimento. No entanto, os valores de níquel obtidos para o córrego B1 colocam este corpo d'água com sedimento de péssima qualidade ambiental.A retirada das matas ciliares parece ter-se refletido também nos elevados valores de temperatura observados na água dos córregos impactados (B1 ao B5). As concentrações de magnésio, manganês, sódio e potássio estão diretamente relacionados com os valores da condutividade elétrica dos córregos. Dessa forma, os resultados obtidos para os valores da condutividade elétrica, também parecem ser um reflexo de atividades agrícolas, uma vez que, nos córregos sem mata ciliar situados em áreas agrícolas, à entrada dos fertilizantes $(\mathrm{N}, \mathrm{P}, \mathrm{K})$ contendo metais, utilizados como micronutrientes, provavelmente influenciou nas concentrações elevadas desta variável na água, como pode ser observado para os córregos B1, B4 e B5, situados nas áreas com cultivo de banana. 
Tabela I. Características gerais e localização geográfica dos 10 córregos estudados.

\begin{tabular}{|c|c|c|c|c|c|c|c|c|}
\hline Municípios & *Córregos & Uso do solo & $\begin{array}{l}\text { Coordenadas } \\
\text { geográficas }\end{array}$ & $\begin{array}{l}\text { Largura } \\
\text { (m) }\end{array}$ & $\begin{array}{c}\text { Profundidade } \\
\text { (cm) }\end{array}$ & $\begin{array}{c}\text { Condutividade } \\
\text { Elétrica } \\
\left(\mu \mathrm{S} . \mathrm{cm}^{-1}\right)\end{array}$ & $\begin{array}{c}\mathrm{O}_{2} \\
\text { dissolv. } \\
\left(\mathrm{mg.L} \mathbf{L}^{-1}\right)\end{array}$ & $\begin{array}{l}\text { Temp. } \\
\left({ }^{\circ} \mathrm{C}\right)\end{array}$ \\
\hline \multirow{2}{*}{ Cajati } & B1 & Banana & $\mathrm{S} 24^{\circ} 50^{\prime} \mathrm{W} 48^{\circ} 14^{\prime}$ & 1.27 & 4.0 & 1.50 & 7.80 & 22,7 \\
\hline & B2 & Banana & $\mathrm{S} 24^{\circ} 50^{\prime} \mathrm{W} 48^{\circ} 14^{\prime}$ & 0.95 & 8.3 & 0.50 & 10.30 & 21,2 \\
\hline \multirow{5}{*}{ Jacupiranga } & B3 & Banana & $\mathrm{S} 24^{\circ} 51^{\prime} \mathrm{W} 48^{\circ} 05^{\prime}$ & 0.52 & 5.0 & 0.05 & 7.87 & 21,7 \\
\hline & B4 & Banana & $\mathrm{S} 24^{\circ} 51^{\prime} \mathrm{W} 48^{\circ} 05^{\prime}$ & 0.78 & 5.0 & 1.13 & 8.45 & 26,2 \\
\hline & B5 & Banana & $\mathrm{S} 24^{\circ} 51^{\prime} \mathrm{W} 48^{\circ} 06^{\prime}$ & 0.82 & 8.5 & 0.82 & 8.51 & 21,2 \\
\hline & M1 & Mata ciliar & $\mathrm{S} 24^{\circ} 59^{\prime} \mathrm{W} 48^{\circ} 02^{\prime}$ & 1.87 & 15.0 & 0.03 & 8.50 & 19,4 \\
\hline & M2 & Mata ciliar & $\mathrm{S} 25^{\circ} 00^{\prime} \mathrm{W} 48^{\circ} 04^{\prime}$ & 2.16 & 14.2 & 0.03 & 9.56 & 19,2 \\
\hline \multirow[t]{3}{*}{ Cananéia } & M3 & Mata ciliar & S $24^{\circ} 57^{\prime} \mathrm{W} 48^{\circ} 59^{\prime}$ & 1.93 & 15.1 & 0.21 & 9.27 & 19,0 \\
\hline & M4 & Mata ciliar & $\mathrm{S} 24^{\circ} 57^{\prime} \mathrm{W} 48^{\circ} 00^{\prime}$ & 1.47 & 13.4 & 0.21 & 9.03 & 19,5 \\
\hline & M5 & Mata ciliar & $\mathrm{S} 24^{\circ} 58^{\prime} \mathrm{W} 48^{\circ} 00^{\prime}$ & 2.71 & 22.1 & 0.24 & 8.20 & 20,4 \\
\hline
\end{tabular}

*B1 a B5 - córregos de cultivos de banana; M1 a M5 - córregos de mata preservada

Tabela II. Concentrações médias de metais potencialmente biodisponíveis $\left(\mathrm{mg}^{\circ} \mathrm{kg}^{-1}\right)$ no sedimento dos 10 córregos estudados.

\begin{tabular}{c|cccccccc}
\hline & Zn & Fe & Cr & Cu & Mn & Mg & Pb & Ni \\
\hline B1 & 75,42 & 2396,23 & 28,29 & 4,74 & 430,85 & 455,36 & 7,81 & 59,37 \\
B2 & 57,98 & 2269,00 & 21,15 & 6,09 & 498,58 & 394,56 & 8,92 & 27,82 \\
B3 & 38,28 & 2136,82 & 17,86 & 6,62 & 422,98 & 382,22 & 11,56 & 15,61 \\
B4 & 28,14 & 2006,06 & 26,91 & 5,12 & 282,88 & 359,21 & 3,32 & 20,18 \\
B5 & 32,90 & 2197,07 & 14,05 & 4,64 & 118,40 & 391,46 & 7,60 & 14,34 \\
M1 & 28,96 & 1901,71 & 5,33 & 1,25 & 116,73 & 286,77 & 6,33 & 6,06 \\
M2 & 31,00 & 1998,13 & 6,72 & 0,37 & 174,87 & 284,79 & 4,99 & 4,97 \\
M3 & 15,92 & 1634,21 & nd & nd & 12,33 & 67,92 & 1,04 & nd \\
M4 & 4,06 & 1477,73 & nd & nd & 6,92 & 53,82 & 1,20 & nd \\
M5 & 4,36 & 1529,09 & 0,99 & 0,14 & 7,46 & 94,51 & nd & nd \\
TEL & 123,10 & sv & 37,30 & 35,70 & sv & sv & 35,00 & 18,00 \\
PEL & 315,00 & sv & 90,00 & 197,00 & sv & sv & 91,30 & 35,90 \\
\hline
\end{tabular}

B1 a B5 - córregos de cultivos de banana; M1 a M5 - córregos de mata preservada. sv = sem valor de referência; nd= não detectado; TEL= nível limiar de efeitos; PEL= nível provável de efeitos. 
Tabela III: Concentrações médias de metais no sedimento de córregos localizados em áreas sob diferentes usos do solo no Estado de São Paulo.

\begin{tabular}{ccccccccc}
\hline & $\mathrm{Zn}$ & $\mathrm{Fe}$ & $\mathrm{Cr}$ & $\mathrm{Cu}$ & $\mathrm{Mn}$ & $\mathrm{Mg}$ & $\mathrm{Pb}$ & $\mathrm{Ni}$ \\
\hline Banana & 46,4 & 22,01 & 21,6 & 5,44 & 350 & 396,4 & 7,8 & 27,4 \\
Banana/com mata ciliar & 16,8 & 17,8 & 2,6 & 0,35 & 63,6 & 14,5 & 2,71 & 2,2 \\
Cana de açúcar & 32,19 & 49,1 & 14,8 & 30,7 & 3,59 & nd & nd & 5,3 \\
Cana/com mata ciliar & 8,42 & 3,3 & 15,6 & 4,3 & 0,48 & nd & nd & nd \\
Pastagem/sem mata ciliar & 45 & 8,25 & 16,6 & 27,2 & 5,25 & nd & nd & 10,1 \\
TEL & 123,10 & $s v$ & 37,30 & 35,70 & $s v$ & $s v$ & 35,00 & 18,00 \\
PEL & 315,00 & $s v$ & 90,00 & 197,00 & $s v$ & $s v$ & 91,30 & 35,90 \\
\hline
\end{tabular}

$\mathrm{sv}=$ sem valor de referência. $\mathrm{nd}=$ não detectado

TEL= nível limiar de efeitos; PEL= nível provável de efeitos (Fonte: [17].

\section{Conclusões}

Apesar das concentrações detectadas no sedimento dos córregos estarem abaixo dos valores-guia de qualidade de sedimentos aquáticos (VGQSs), as maiores concentrações observadas nos córregos com atividade de banana apresentam indício de um problema que tem sido ocasionado por atividades agrícolas que utilizam fertilizantes em áreas próximas aos córregos sem matas ciliares. Esse conjunto de atividades tem acarretado a contaminação por metais em recursos hídricos de várias regiões do Estado de São Paulo. As maiores concentrações de metais nesses sistemas, ainda que dentro dos valores-guia de qualidade, evidenciam a necessidade de um manejo adequado dos recursos hídricos, com o reflorestamento das matas ciliares. Esses resultados também tornam evidente a necessidade da adoção de outros métodos de fertilização do solo, contendo menores concentrações de metais, ou ainda, a substituição de tais métodos por outros naturais como, por exemplo, a rotação de culturas e/ou produção orgânica na agricultura. Essa situação parece ser fundamental para os ambientes com cultivo de banana, uma vez que as concentrações detectadas no sedimento dos córregos foram mais elevadas se comparados também a outras atividades agrícolas como canade-açúcar e áreas de pastagens no Estado de São Paulo. Além disso, esse estudo aponta para a necessidade da elaboração de um sistema padrão que utilize o sedimento aquático como parte importante nos estudos de avaliação ambiental, uma vez que inúmeros organismos aquáticos, como macroinvertebrados bentônicos, se utilizam deste compartimento aquático como local de sobrevivência e alimentação, podendo ser contaminados por metais e transferir, através da biomagnificação, essa contaminação para outros grupos animais como peixes e aves. 
Agradecimentos. Aos fazendeiros da região que permitiram livre acesso nas suas propriedades para as coletas de sedimento dos córregos. Ao Prof. Dr. Pedro Paulo Corbi pela revisão do trabalho. Financiamento CNPq.

\section{Referências}

[1] Silva, S.F.; Dissertação de Mestrado, Escola de Engenharia de São Carlos, São Carlos, 2000.

[2] Allan, J.D.; Erickson, D.L.; Fay, J.;

Freshwater Biol. 1997, 37:149.

[3] Meybeck, M.; Helmer, R. An introduction to water quality. In: Water Quality Assessments. A Guide to Use of Biota, Sediments and Water in Environmental Monitoring. Cambridge:

University Press, 1996.

[4] Corbi, J.J.; Froehlich, C.G.; Trivinho-Strixino,

S.; Dos Santos, A.; Environ. Monit. Asses, 2011. DOI 10.1007/s10661-010-1655-5

[5] Corbi, J.J.; Trivinho-Strixino, S.; Dos Santos,

A.; Del Grande, M.; Quim. Nova, 2006, 29, 61.

[6] Corbi, J.J.; Froehlich, C.G.; Trivinho-Strixino,

S.; Dos Santos, A.; Quim. Nova, 2010, 33(3): 644.

[7] Silva, S.; Tassara, H. Frutas Brasil Frutas. São

Paulo: Empresa das Artes, 2005.

[8] Instituto de Economia Agrícola. Série Informações Estatísticas da Agricultura (2005).

Disponível em:

<http://www.iea.sp.gov.br/out/publicacoes/anuari o.php>. Acesso em: 19 de fevereiro de 2007.

[9] Alves, E.J. Cultivo de Bananeira tipo terra.

Cruz das Almas: Embrapa Mandioca e Fruticultura, 2001.

[10] Souza, K.C.M.; Dissertação de Mestrado, Universidade Estadual de Campinas, Campinas, 2000.

[11] Angelotti-Netto, A.; Crestana, S.; De Oliveira, S.C.; Barbosa, R.V.R; Bacia

Hidrográfica. Rima Editora, São Carlos, 2004.

[12] Santos, A.; Dissertação de Mestrado, Universidade de São Paulo. Brasil, 1999.

[13] Corbi J.J.; Trivinho-Strixino, S.; Braz. Arch. Biol. Technol. 2008, 51(4): 769.

[14] Borges, A.L.; Oliveira, A.M.G.; Souza, L.S. Solos, nutrição e adubação. In: A cultura da banana: aspectos técnicos, socioeconômicos e agroindustriais. Brasília: Embrapa-SPI, 1997. [15] Myers, N.; Mittermeier, R.A.; Mittermeier, C.G.; Fonseca, G.A.B.; Kent, J.; Nature, 2000, $403,853$.

[16] Förstner, U.; Wittmann, G. T. W.; Metal pollution in the aquatic environment. 2 nd revised ed., 1983.

[17] Mozeto, A.P.; Umbuzeiro, G. A.; Jardim, W. F. Métodos de coleta, análises físico-químicas e ensaios biológicos e ecotoxicológicos de sedimentos de água doce, $1^{\mathrm{a}}$ ed., Ed. Cubo, São Carlos, 2006.

[18] Magalhães, N.W. Descubra o Lagumar. São Paulo: Terragraph Artes e Informátca S/C Ldta. 1998.

[19] Kleine, P., Corbi, J.J., Trivinho-Strixino, S., Acta Limnol. Bras., 2012.

http://dx.doi.org/10.1590/S2179-

975X2012005000012.

[20] Secretaria do Meio Ambiente do Estado de São Paulo. Macrozoneamento do complexo estuarino-lagunar de Iguape e Cananéia: plano de gerenciamento costeiro. São Paulo: SMA, 1990.

[21] Tschöpel, P.; Kotz, L.; Shulz, W.; Veber, M.; Tölg, G.; Fres. J. Anal. Chem. 1980, 302, 1.

[22] Malavolta, E.; Fertilizantes e seu impacto ambiental: micronutrientes e metais pesados, mitos, mistificações e fatos. São Paulo: Produquímica, 1994.

[23] De Paula, F.C.F.; Mozeto, A.A.; Applied Geochem. 2001, 16, 1139.

[24] Peláez-Rodríguez, M.; Tese de Doutorado, Universidade de São Paulo (USP), 2001.

[25] Barreto, A. dos S.; Tese de Doutorado, Universidade de São Paulo, Brasil, 1999.

[26] Batalha, B. L.; Parlatore, A. C.; Controle da qualidade da água para consumo humano. São Paulo, Cetesb, 1993.

[27] Canto, E. L.; Minerais, Minérios e metais: de onde vem para onde vão? Ed. Moderna, São Paulo, 1997. 
[28] Ziolli, et. al.; $18^{a}$ Reunião anual da Sociedade Brasileira de Química e $7^{\circ}$ encontro Brasileiro de fotoquímica e fotobiologia, 1995, Anais.
[29] CETESB; Sedimento em redes de monitoramento. Relatório técnico. São Paulo, 178p. 2007. 